\title{
A Study of the Level of Special Knowledge of Rural Women Small Productive Projects and the Most Important Activities Provided by the Social Fund in Yemen
}

\author{
Haifa Al-Sanabani ${ }^{1 *}$, Saeed A M Rashad ${ }^{2}$ and Hassan Mohamed Gado ${ }^{3}$ \\ ${ }^{1}$ Department of Economics and Development, Faculty of Agriculture, Thamar University, Yemen \\ ${ }^{2}$ Professor of Agricultural Extension and Head of the Agricultural Economics Department, Banha University, Egypt \\ ${ }^{3}$ Professor of Agricultural Economics, Faculty of Agriculture, Banha University, Egypt \\ *Corresponding author: Haifa Al-Sanabani, Assistant professor, Department of Economics and Development, Faculty of Agriculture, \\ Thamar University, Yemen
}

\section{ARTICLE INFO}

Received: 䋓 July 01, 2021

Published: 慧 July 19, 2021

Citation: Haifa Al-Sanabani, Saeed A M Rashad, Hassan Mohamed Gado. A Study of the Level of Special Knowledge of Rural Women Small Productive Projects and the Most Important Activities Provided by the Social Fund in Yemen. Biomed J Sci \& Tech Res 37(2)-2021. BJSTR. MS.ID.005977.

Keywords: Knowledge Level of Rural Women; Small Productive Projects; Social Fund in Yemen
ABSTRACT

This study aims to identify the level of knowledge of rural women in small productive projects and the most important activities provided by the Social Fund in Yemen, and determine the relationship between the cognitive level and some independent variables studied, with the contribution of each of these independent variables morally related to the cognitive level This variable, as well as identify the most important problems facing the beneficiaries of the Social Fund loans in Yemen and their proposals to resolve. This research was conducted in Sana'a Governorate and four districts were selected: Bani Matar, Bani Hashish, Jahana and Al Hima. A random sample of 154 women was selected, representing $5 \%$ of all rural women in the four departments. The study data were collected from the middle of March 2018 to May 2018 by means of the interview by questionnaire form after being tested in principle. The statistical analysis was used: the arithmetic mean, the periodic width of the frequencies and percentages, the simple correlation coefficient of Pearson, and the incremental correlation and regression model.

\section{The Main Results of the Study Can Be Summarized as Follows}

$37.7 \%$ of rural women are in the category of low knowledge, $37.7 \%$ of them are in the category of medium knowledge and $25.3 \%$ of them are in the category of high knowledge. and the overall average degree of rural women's knowledge was 1.10 degrees by 54.86 The results showed that the percentage of the contribution of the independent variables studied together in the interpretation of the total variance of the level of knowledge of the subjects with the information items of the small productive projects and the main activities provided by the Social Fund was $99.4 \%$, of which $70.1 \% \%$ a The degree of trend towards small enterprises, $10.2 \%$ to informal social participation, and $1.2 \%$ to the degree of exposure to sources of information and the mass media. The results of the study also showed that there are problems facing the beneficiaries of the social fund loans in Yemen. The most important of these problems are the lack of training programs suitable for the nature of the project, the inability to pay the loan on time, the inability to market or export the product, The respondents also referred to some proposals to overcome such problems, the most important of which is the provision of a database on investment projects, shortening the procedures for disbursing the loan, providing means of transport through cooperative marketing associations and holding training courses for borrowers during their projects. 


\section{Introduction and Research Problem}

Development is an essential, imperative, and national requirement for all countries of the third world, and it is characterized by a general and continuous nature, that is, once it ends at a certain level until it begins again from where it ended and with tools and means dominated by the characteristic of modernization and renewal to suit the dynamic reality of the permanent community, and aims to advance the economic level The social, health, educational and cultural through the optimal utilization of all human and material resources and multi-pronged development. Improving income levels and increasing productivity require changes in the economic and social structure and a change in the value frameworks of the population and must be comprehensive in order for them to be sustainable [1].

Given the importance of the agricultural sector in rural areas as one of the most important sectors able to provide new job opportunities for the rural community by exploiting the available natural resources, by setting up small agricultural projects in the field of inputs and requirements for agricultural, animal and craft operations and the circulation, marketing and manufacture of their outputs, the Yemeni state and the fund have adopted Social Development Group has a set of development programs to solve these problems, especially in the Yemeni countryside, which contains many small productive projects and development activities that work on comprehensive development, with what they achieve of great benefits represented in: increasing the income of the majority of the population, improving their standard of living and increasing job opportunities, Participation of rural residents in various projects, and the implementation of these projects through cooperatives as well as commercial and specialized banks such as the Al-Amal Microfinance Bank and the National Microfinance Foundation and other banks for microfinance. The projects under implementation in most of the governorates of the Republic of Yemen were covered [2].

Cognitive changes play an important role in the success of development projects in achieving their economic and social goals, as modifying the individual's cognitive framework has an important role in his participation in various development activities [3]with the consequent increase in their incomes and thus raising the level of their family living. To achieve the goals of rural development, many bodies and organizations have been established in many Arab countries that contribute to achieving these goals and then the development of the rural community [4]. Agricultural extension is considered one of the most important organizations that work to advance the countryside through many roles that it performs, either individually or collectively, and is to: take advantage of all the opportunities, resources and natural and human capabilities, education and awareness of rural people, develop their capabilities, improve their skills, and change their attitudes so that they can benefit Full of technology developed, which contributes to raising the living standards of these individuals.

Qualified and trained human resources are the critical element in the development issue, as development experiences have proven that building modern societies depends primarily on the level and quality of their human resources, and that the success of development efforts depends on the active participation of all human energies, both men and women, in these efforts. And rural women have a prominent role in agricultural production, through the practice of actual work or their contribution to opinion in agricultural investment methods and means, and the participation of men in agricultural decisions in the family, which would increase the family's income and raise the standard of living. The World Food Conference makes clear that $50 \%$ of women in developing countries contribute to food production, but that food work is usually not taken into account for being unpaid work [5]. This is what motivated those responsible for thinking about establishing the Social Fund for Development, and one of the first tasks of the job was training and rehabilitation for rural women through work and organizing extension and development programs for productive families and focusing on women and girls from poor families in need through training courses in different areas and helping them to help themselves And providing them with job opportunities.

The Social Fund for Development is one of the pillars that depend on it in achieving rural development through its methods, means and mechanisms in all aspects of rural life, among which is the concern for rural women through what it provides to them with loans and training that may be reflected in changing knowledge, practices and attitudes they have through presenting projects Small income-generating that leads to the integration of rural women in society, which makes them feel entity and themselves in that they achieve additional income that helps the family and thus enables them to participate and effectively in family decisions and social upbringing of family members and the formation of a healthy generation capable of bearing the burdens. By analyzing the vision and strategy, the financing tasks and activities undertaken by the Social Fund for Development in this field, especially in rural activities related to food and small-scale crafts industries and loans to rural women in this regard, it was noted in general that there is no clear vision or specific strategy for this matter, especially towards rural women.

From this standpoint, the need to conduct this research has emerged on rural women, and therefore the research problem has evolved in the following questions: What is the prevailing knowledge level of rural women in relation to small productive projects and what are the most important activities provided by the Social Fund in Yemen)? What is the effect of some personal, economic and social variables on the knowledge of rural women related to small 
productive projects and the most important activities provided by the Social Fund in Yemen)? What are the most important problems facing female respondents benefiting from social fund loans in Yemen and their proposals for solving them? And answering the previous questions may lead to the clarification of the truth about the knowledge of rural women related to small productive projects and the most important activities provided by the Social Fund in Yemen and some of the related variables, in addition to that there is a clear lack in the volume of studies that dealt with the knowledge levels of rural women and related to the activities studied in Yemen In order to be able to meet its educational and training needs in this vital field.

\section{Research Objective}

Based on the research problem mentioned above, its objectives can be determined as follows: -

a. Knowing the prevailing knowledge of rural women related to small productive projects and the most important activities provided by the Social Fund in Yemen.

b. Determine the relationship between the degree of knowledge prevalent among rural women and related to small productive projects and the most important activities provided by the Social Fund in Yemen and each of the following studied independent variables: age, degree of education, degree of formal social participation, degree of informal social participation, degree of openness to The outside world, the degree of exposure to information sources and the mass media, the degree of exposure to the activities of the social fund, the degree of direction towards small productive projects, the degree of opinion of the researchers regarding the educational and social effects that can occur as a result of the application of small productive projects, the degree of educational and social returns achieved for small production projects From the point of view of rural women.

c. Determine the contribution rates of each of the independent variables with a significant correlation with knowledge related to small productive projects for rural women in explaining the total variance.

d. Knowing the most important problems facing female respondents who benefit from social fund loans from the point of view of rural women.

e. To get acquainted with the most important proposals needed to solve the problems facing female respondents who benefit from Social Fund loans from the point of view of rural women.

\section{Procedural Definitions Used in the Research}

Rural Women: In this study, it means participants who participated in courses and training in all agricultural and craft extension and development activities as well as agricultural and non-craft development projects.

The Degree of Knowledge: This study refers to the extent of knowledge of rural women in all items of knowledge and information related to small productive projects and the most important activities provided by the Social Fund in Yemen to increase the knowledge of rural women in the small project.

Rural Women who are Beneficiaries of the loans of the Social Fund for Development projects: they are the individuals who interact with the associations of the districts. Loans have been disbursed to them from the Social Fund project, and they carry out: a production activity or several production activities.

Formal Social Participation: this study means the degree of participation of rural women in agricultural and developmental community membership in a local council, cultural center or political party, and knowledge of their participation with a type of membership.

Informal Social Participation: this study means the degree to which rural women are able to exchange visits and interact with women from their village.

Opening Up to the Outside World: means visits made by the respondent to visit the city that follows her village, visiting the capital of the governorate that belongs to the respondent, visiting other provinces, making trips outside Yemen, to know the degree of openness to the outside world among rural women.

Exposure to Information Sources and the Mass Media: It refers to the various channels and means of communication that rural women are exposed to in order to obtain the information they need about activities and programs related to small agricultural and craft development projects.

Participation in the Activities Provided by the Social Fund for Development: it refers to the activities carried out by the Social Fund for Development in which rural women participate in order to obtain the information they need about the activities and programs of agricultural development projects and small craftsmanship.

The Trend towards Small Productive Projects: This refers to the extent of the inclination of rural women who are supportive, opposed or neutral towards some expressions that reflect the facts, knowledge, behaviors and trends associated with small agricultural and craft development projects.

The Degree of the Respondents' Opinion regarding educational and social effects that can occur as a result of applying small productive projects: In this study, the opinion of the respondents is understood to be approvals, rhetoric, or nonapprovals of sixteen terms that represent the set of educational as well as social returns that can occur As a result of applying small production projects. 
The Extent to Which Educational and Social returns have been achieved for small productive projects from the point of view of rural women: this study refers to the responses of the respondents, which ranged between complete verification, partial verification, or lack of verification about sixteen terms that revolve around both social and educational returns for small productive projects, according to Self-assessment of the respondents.

\section{Research Hypotheses}

\section{Theoretical Assumptions:}

A. There is a significant relationship between the degree of the female respondents' knowledge of the information items for small productive projects and the most important activities provided by the Social Fund for Development and the following independent variables: age, degree of education, degree of formal social participation, degree of informal social participation, degree of openness to the outside world, degree of Exposure to information sources and mass media, degree of exposure to social fund activities, degree of trend towards small productive projects, degree of opinion of respondents regarding educational and social effects that can occur as a result of implementing small productive projects, degree of educational and social returns achieved for small production projects from a women's viewpoint Rural.

B. Each of the independent variables with significant correlations with the degree of rural women's knowledge of information items related to small productive projects and the most important activities provided by the Social Fund in Yemen contribute to explaining the total variance.

\section{Statistical Assumptions}

A. There is no significant relationship between the degree of the female respondents' knowledge of the information items for small productive projects and the most important activities provided by the Social Fund for Development and the following independent variables: age, degree of education, degree of formal social participation, degree of informal social participation, degree of openness to the outside world, The degree of exposure to information sources and the mass media, the degree of exposure to the activities of the Social Fund, the degree of direction towards small productive projects, the degree of the opinion of the researchers regarding educational and social effects that can occur as a result of the application of small productive projects, the degree of educational and social returns achieved for small productive projects from the point of view Rural women.

B. Each of the independent variables with significant correlations with the degree of rural woman's knowledge of information items related to small productive projects and the most important activities provided by the Social Fund in Yemen do not contribute to the interpretation of the total variance.

\section{Research Methodology}

Sana'a governorate was chosen to conduct this research, and given the breadth of the governorate, four directorates were chosen from them: directorates: Bani Matar, Bani Hashish, Juhana, external circumvention according to the material capabilities of the researcher and their inability to collect data from all the mentioned directorates. To determine the sample of rural women in order to obtain the data necessary to achieve the goals of the study, a random sample $(5 \%)$ of the total number of clients with associations in the Social Fund for Development project was selected, through benefiting from social fund associations loans or other alternative sources, and the sample size reached about (156) respondents, out of their total number of about (3128) respondents, at a rate of $5 \%$ of the total number of respondents in the four directorates, and they were chosen in a systematic, random way from the reality of the statements of the Social Fund for Development in the directorates under study, and they are distributed according to the previous percentage as follows: 53 in the Directorate Bani Matar, 57 Bani Hashish, 36 Juhana, 10 outside neighborhood. The number of (2) forms was excluded due to incomplete data, and the final sample size became (154) respondents distributed as follows: 53 in Bani Matar District, 56 Bani Hashish, 35 Juhana, 10 external virginity.

The study data was collected from mid-March 2018 to May 2018 through a personal interview by means of a questionnaire after it was initially tested, and was used to statistically analyze the data: the arithmetic mean, the tabular presentation of the frequencies and the percentages, the simple correlation coefficient of Pearson and the polymorphic regression and multiple upward regression model.

\section{Results and Discussion}

\section{The Knowledge of Rural Women about Information}

Items related to small productive projects and the most important activities provided by the Social Fund in Yemen To determine the knowledge of the rural woman who was researched about the information items related to small productive projects and the most important activities provided by the Social Fund in Yemen, she was asked about a number of information items related to these projects as shown in the research method, and by using the sum of the values of the phrases obtained from the responses of the respondents to the inquiries related to With the information items, the theoretical grades of the scale were confined between, the theoretical grades of the scale were confined between a minimum of zero and a maximum of 66 degrees, while the actual and obtained grades of the respondents' response were limited to a maximum of 46 degrees and a minimum value of 29 degrees With an average mean of 36.21 degrees, and a standard deviation of 5.15. Accordingly, the studies were classified into three categories according to their total score, expressing their knowledge of the 
items of information related to small productive projects and the most important activities provided by the Social Fund as shown in Table 1 Are
a. Low knowledge (less than 35 degrees)
b. Moderate Knowledge (35 - less than 41 degrees)
c. High knowledge (41 degrees or more)

Table 1: Distribution of surveyed according to the categories of their knowledge of information items Small productive projects and the most important activities provided by the Social Fund for Development.

\begin{tabular}{|c|c|c|}
\hline List Categories of knowledge surveyed & No & \% \\
\hline Low Knowledge (less than35 degree) & 57 & 37 \\
\hline Medium Knowledge (less than 41 degree & 58 & 37.7 \\
\hline high knowledge (more than 41 degree) & 39 & 25.3 \\
\hline Total & 154 & 100 \\
\hline
\end{tabular}

The results shown in the same table show that $37 \%$ of the respondents fall in the group with low knowledge, $37.7 \%$ of them fall in the category with medium knowledge and that $25.3 \%$ of them fall into the category with high knowledge. These results indicate that $74.7 \%$ of the respondents were of low and medium knowledge of the information items for small productive projects and the most important activities provided by the Social Fund, which may indicate the need to guide them with programs aimed at increasing their knowledge of these items in order to be able to apply this knowledge Thus obtaining a high income and high income that will achieve a stable life for them, also the existence of an educational knowledge need for them means that there is a wide scope for indicative activity through the Social Fund for Development to work to address the deficiencies in the knowledge of the researchers and their awareness, and amend their knowledge structure in relation to the activities of small production projects that have shown The study indicates that the knowledge of the respondents was low and medium, and this requires planners, implementers of extension programs and employees of the Social Fund for Development to take this into account when planning guidance programs aimed at familiarizing the respondents with knowledge and information about small productive projects in the study area in Yemen.

To get acquainted with the degree of knowledge of the respondents for each item of information for items related to small productive projects and the most important activities provided by the Social Fund, the average scores for this knowledge were calculated for each item of the studied information, where the averages of the degrees of their knowledge of this information were limited to 0.4 degrees as a minimum by $1.95 \%$, And a maximum score of $100 \%$ by $100 \%$, and this confirms what the results indicate from the actual average height above the theoretical average of the degree of knowledge where the theoretical average is limited to one degree between a minimum of two and a maximum of two degrees while the overall average of the levels of the respondents' knowledge of the project information items was Small productivity is 1.10 degrees, at $54.86 \%$. The information items for small productive projects and the most important activities provided by the Social Fund in terms of averages of degrees of female researchers' knowledge have been divided into three categories as shown in Table 2, namely:
A. Low knowledge (less than 0.69 degrees)
B. Moderate knowledge (0.69 - less than 1.34 degrees)
C. Knowledge is high (1.34 degrees or more)

Table 2: The Numerical Distribution of Information Materials for Small and Medium Enterprises and Projects Affiliated with the Social Fund for Development.

\begin{tabular}{|c|c|c|}
\hline $\begin{array}{c}\text { List of Categories of knowledge } \\
\text { surveyed }\end{array}$ & $\begin{array}{c}\text { Number of } \\
\text { information items }\end{array}$ & $\%$ \\
\hline $\begin{array}{c}\text { Known information is low (less than } \\
69.0 \text { degree) }\end{array}$ & 8 & 24.2 \\
\hline $\begin{array}{c}\text { Known information is medium (0.69- } \\
\text { less than 1.34 degrees)) }\end{array}$ & 13 & 39.4 \\
\hline $\begin{array}{c}\text { Known information is high (more than } \\
1.34 \text { degree) }\end{array}$ & 12 & 36.4 \\
\hline Total & 33 & 100 \\
\hline
\end{tabular}

It was found that $24.2 \%$ of the information items on small productive projects and activities provided by the Social Fund were of low knowledge, while it was found that $39.4 \%$ of information items on small production projects and activities provided by the Social Fund were of medium knowledge, while $36.4 \%$ of Items of information for small productive projects and the most important activities provided by the Social Fund. It was found that $24.2 \%$ of the information items on small productive projects and activities provided by the Social Fund were of low knowledge, while it was found that $39.4 \%$ of information items on small production projects and activities provided by the Social Fund were of medium knowledge, while $36.4 \%$ of Items of information for small productive projects and the most important activities provided by the Social Fund. It was clear from Table 3 that the items of information for small production projects and the most important activities provided by the Social Fund for Development for which the average levels of knowledge of the respondents were low are: a project to provide the requirements of agricultural production, and the average degree of knowledge of the researchers for this item was 0.51 degrees by $2532 \%$, and the item on a project to produce seedlings and the establishment of nurseries for fruit and ornamental trees and coffee 0.31 degrees by $15.26 \%$, as well as knowledge about the item on government banks, and the average degree of knowledge of the researchers for this item was 0.42 degrees by $20.78 \%$, while none of the respondents were known 
The item on commercial banks, the average level of knowledge of respondents for the training of beneficiaries item was 0.42 degrees by $20.78 \%$, the item for providing technical assistance to the small project 0.42 degrees by $20.78 \%$, the item for wholesalers is 0.04 degrees by $1.95 \%$, and the item for wholesale markets $0.041 .95 \%$ score.

Table 3: Averages and percentages of the respondents' knowledge of the information items related to small productive projects and the most important activities provided by the Social Fund for Development.

\begin{tabular}{|c|c|c|c|}
\hline Information items for small production projects & $\begin{array}{l}\text { Average knowledge } \\
\text { degree }\end{array}$ & $\% *$ & Level of knowledge \\
\hline One million Yemeni riyals (small project). & 1.17 & 58.44 & Medium \\
\hline $\begin{array}{c}\text { The project, which has a loan amount available between } 100,000 \text { and } \\
200,000 \text { Yemeni riyals, is considered a very small project }\end{array}$ & 0.82 & 40.91 & Medium \\
\hline Cattle fattening project for providing red meat & 1.27 & 63.64 & Medium \\
\hline providing milk Project for provide dairy products & 1.65 & 82.47 & High \\
\hline Poultry farming project & 2 & 100 & High \\
\hline Providing agricultural production requirements project & 0.51 & 25.32 & low \\
\hline $\begin{array}{l}\text { Production and establishment of nurseries for fruit, ornamental and coffee } \\
\text { tree project }\end{array}$ & 0.31 & 15.26 & high \\
\hline Food industry project & 2 & 100 & high \\
\hline Honey production project & 1.18 & 59.09 & Medium \\
\hline $\begin{array}{l}\text { A craft project such as (sewing, knitting, embroidery, kawafeer and and } \\
\text { Nagish AL Huna }\end{array}$ & 2 & 100 & high \\
\hline Increase in all kinds of livestock products & 0.86 & 42.86 & Medium \\
\hline Provides new job opportunities & 0.86 & 42.86 & High \\
\hline Encouraging investment in various fields (agricultural, craftsmanship) & 0.92 & 46.1 & Medium \\
\hline Ensure food and social security & 0.82 & 40.91 & Meduim \\
\hline raise all kind of products such as (sewing, embroidery, knitting, etc.) & 1.58 & 79.22 & High \\
\hline It contributes on the operation of unemployed & 1.17 & 58.44 & Medium \\
\hline It contributes to improving family assets. & 1.65 & 82.47 & high \\
\hline It helps to gain new knowledge and experience for project management & 2 & 100 & Meduim \\
\hline Make a better life than before. & 1.69 & 84.42 & High \\
\hline Government banks. & 0.42 & 20.78 & low \\
\hline Social Fund for Development & 1.47 & 73.7 & high \\
\hline Commercial bank & 0 & 0 & low \\
\hline Microfinance programs and institutions & 1.69 & 84.42 & high \\
\hline Providing soft loans & 0.77 & 38.31 & Medium \\
\hline Training of beneficiaries & 0.42 & 20.78 & Low \\
\hline Providing technical assistance to the small project & 0.42 & 20.78 & Low \\
\hline $\begin{array}{l}\text { Raising awareness among women of the importance of establishing, } \\
\text { owning and managing small projects as a choice for the future }\end{array}$ & 1.69 & 84.42 & High \\
\hline Knowing Product Marketing & 2 & 100 & low \\
\hline Village markets & 1.17 & 58.44 & Medium \\
\hline Local markets & 0.73 & 36.36 & Medium \\
\hline Exhibitions held by marketing sponsors & 0.92 & 46.1 & Medium \\
\hline Wholesalers. & 0.04 & 1.95 & Low \\
\hline Wholesale markets & 0.04 & 1.95 & Low \\
\hline Overall average & 1.1 & 54.86 & \\
\hline
\end{tabular}

Note: Source: collected and calculated from field study data. 
It has also been found that the most important items of information for small productive projects and the most important activities provided by the Social Fund for Development, for which the average levels of knowledge of the subjects were average: the item for the project with a loan amount of between 300 thousand to one million Yemeni riyals (a small project), and it was The average knowledge of the respondents for this item is 1.17 degrees with a rate of $58.44 \%$, and the item for the project that has a loan amount of between 100 thousand to 200 thousand Yemeni riyals is considered a very small project, and the average degree of knowledge of the researchers has 0.82 by $40.91 \%$, as well as the item for the fattening project Cattle to provide red meat 1.27 degrees, 63.64\%, and for a honey production project, the average level of knowledge of the respondents for this item was 1.18 degrees, by $59.09 \%$, and the average degree of knowledge of the respondents for an item representing an increase in livestock products of all kinds was 0.86 degrees, with percentage of $83 \%$, and the item For the provision of new job opportunities, 0.86 degrees, with a percentage of $143 \%$, and the item for encouraging investment in various fields (agricultural, craftsmanship) 0.92 degrees, by $46.10 \%$, and the item for achieving food and social security, 0.82 degrees, bin The percentage of $40.91 \%$, the item on contributing to the employment of unemployed hands is 1.17 degrees at $58.44 \%$, the item on providing soft loans is 0.77 degrees at $38.31 \%$, the item on exhibitions held by the marketing financing agencies is 0.92 degrees or $46.10 \%$, and the item on local markets was average The degree of the female respondents was 0.73 , or $36.36 \%$, and also the item for the village markets. The average degree of female respondents was 1.17 , or $58.44 \%$.

It turned out that the information items for small productive projects and the most important activities provided by the Social Fund for Development, for which the average levels of knowledge of the respondents were high are: The item for the project to provide milk for the provision of milk, and the average degree of knowledge of the subjects for this item was 1.65 degrees by $82.47 \%$, as well as the item For the project for poultry raising, and the average degree of knowledge of the researchers for this item was 2 degrees by $100 \%$, and also the item for the food industries project, and the average degree of knowledge of the subjects for this item was 2 degrees by $100 \%$, and the item for a handicraft project such as (stitching, sewing, embroidery , Cover and engraving) The average degree of the respondents was 2 degrees by $100 \%$, and also the item for increasing the products of all kinds (sewing, embroidery, sewing, etc.), and the average degree of the respondents' knowledge was 1.58 degrees by $79.22 \%$, and for an item that contributes to improving family assets, the average degree was The respondents 'knowledge of this item is 1.65 degrees, at a rate of $82.47 \%$, and the average degree of female respondents' knowledge of an item that has been able to acquire new knowledge and expertise for project management is 2 points at $100 \%$, and the item for achieving life a Preferred from 1.69 degrees by $84.42 \%$, the item for the Social Fund for Development 1.47 degrees by $73.70 \%$, the item for microfinance programs and institutions 1.69 degrees by $84.42 \%$, and the special item to deepen awareness among women of the importance of establishing, owning and managing small projects as a choice for the future 1.69 degrees by $84.42 \%$, The item on knowledge of marketing products 2 degree $100 \%$.

The previous results indicate that there is a knowledge gap and a strong need among rural women in the field of small productive projects, which requires planners and implementers of extension programs and the Social Fund for Development to take into account what the results of the study showed when planning and implementing extension programs so that rural women can succeed in the field of projects The small productivity it implements and raises its standard of living.

\section{The Relationship Between the Degree of the Female Respondents'}

The relationship between the degree of the female respondents' knowledge of information items related to small productive projects and the most important activities provided by the Social Fund for Development with the studied independent variables. This part is concerned with presenting the most important findings of the research, which relate to testing the correlation between the degree of the researchers' knowledge of information on small productive projects and the independent variables under study, namely: age, degree of education, degree of official social participation, degree of informal social participation, degree of openness to The outside world, the degree of exposure to information sources and the mass media, the degree of participation in the activities provided by the Social Fund, the degree of direction towards small productive projects, the degree of opinion of the researchers regarding the educational and social effects that can occur as a result of the application of small productive projects, the degree to which educational and social returns are achieved for projects Small productivity from the perspective of rural women.

To study this relationship, the first statistical hypothesis was formulated that "there is no significant relationship between the degree of the female respondents' knowledge of information items related to small productive projects and the most important activities provided by the Social Fund for Development and the previously mentioned independent variables. "To test the validity of this hypothesis, Pearson's simple correlation coefficient was used. Table 4 data show a significant relationship at level 0.01 of the level of informal social participation, the degree of exposure to information sources and mass media, the degree of participation in social fund activities, the degree of direction towards small projects, and the degree of He saw the subjects regarding educational and social effects that could occur as a result of implementing small productive projects. 
Table 4: The values of the correlation coefficients between the level of knowledge of the respondents about the information items related to small productive projects and the most important activities provided by the Social Fund for Development.

\begin{tabular}{|c|c|c|}
\hline $\mathbf{N}$ & The studied independent variables & Correlation coefficient values \\
\hline 1 & age & 0.132 \\
\hline 2 & The degree of education of the surveyed & 0.003 \\
\hline 3 & The degree of official social meeting & 0.007 \\
\hline 4 & The degree of informal social meeting & $* 0.523$ \\
\hline 5 & The degree of openness to the outside world & $* 001$ \\
\hline 6 & participation's degree in the activities of the social fund & $* * 0.263$ \\
\hline 7 & tendency's degree towards small projects & $* * 0.837$ \\
\hline 8 & of the application of small productive projects & $* * 0.822$ \\
\hline 9 & $\begin{array}{c}\text { The degree of opinion of the surveyed regarding the educational and social effects that may occur as a result } \\
* * 0.276\end{array}$ \\
\hline 10 & $\begin{array}{r}\text { The degree of achievement of educational and social returns for small productive enterprises from the point } \\
\text { of view of rural women }\end{array}$ & \multirow{2}{*}{0.004} \\
\hline
\end{tabular}

Note: The value of the tabular correlation coefficient $\mathrm{DH}=$ At a morale level 152: It 0157 ‘0.207

- $\quad$ a morale level at 10.05

- $\quad$ a morale level at 0.01

Whereas, they were not related to the other studied independent variables, which are: age, degree of education, degree of formal social participation, degree of openness to the outside world, and degree of educational and social returns to small productive projects from the point of view of rural women.

Based on this result, the statistical assumption can be partially rejected and the alternative hypothesis accepted, and there is a moral relationship between both the degree of informal social participation, the degree of exposure to information sources and the mass media, the degree of participation in social fund activities, the degree of direction towards small projects, and the degree of opinion of the respondents with It relates to the educational and social effects that can occur as a result of the application of small productive projects and between the degree of the female respondents' knowledge of the information items of the small productive projects and the most important activities provided by the Social Fund for Development, and this may be due to the greater the degree of participation of the informal social research and the degree of its exposure to sources of information and media The masses, the degree of their participation in the activities of the social fund, the degree of their direction towards small projects, and the degree of their opinion regarding educational and social effects that can occur as a result of implementing small productive projects. The more they become aware of the importance of small production projects and the greater their desire to obtain knowledge and innovations in this field, especially the research Young women are young And those who are expected to deal in the field of small projects for a longer period than the elderly, and therefore they become more eager to increase their knowledge in this field.

\section{Determining the Percentages of the Contribution of the Variables}

Determining the percentages of the contribution of the variables that have a moral correlation with the degree of the female respondents' knowledge of the information items related to small productive projects and the most important activities provided by the Social Fund and to make sure of the previous results indicating that there is a significant relationship between the degree of the female researchers' knowledge of the information items for small productive projects and the most important activities provided by the Social Fund for Development and between the independent variables with a moral relationship with them and make them more accurate in light of the dynamics of other variables, and by taking the impact of these variables into consideration, The following statistical hypothesis has been put in place that "each of the independent variables with significant correlations with the degree of knowledge of rural women does not contribute to information items related to small productive projects and the most important activities provided by the Social Fund in the overall explanation of the variance and these variables are: the degree of informal social participation, and the degree of exposure For sources of information and mass media, the degree of participation in the activities of the Social Fund, the degree of direction towards small projects, and the degree of opinion of the respondents regarding educational and social effects that may occur as a result of the application of small productive projects.

To test the validity of this hypothesis and to estimate the contribution rates of each of the independent variables with a moral relationship with the degree of the researchers' knowledge 
of the information items for small productive projects and the most important activities provided by the Social Fund for Development in the overall explanation of variance, use the model of correlative and regression of the progressive multiple regression, which proved that there are nine Independent variables with a moral relationship in the interpretation of all the moral variables to which the conditions apply are: the degree of participation in social fund activities, the degree of direction towards small projects, the degree of informal social participation, the degree of exposure to information sources and the mass media, and from the results of the analysis shown in Table 5 It was clear that the percentage of the contribution of these variables to the explanation of the total variance of the degree of the respondents' knowledge of information items related to small projects was $99.4 \%$, of which $70.1 \%$ was attributed to the degree of participation in the activities of the social fund, and $17.9 \%$ to the degree of trend towards small projects, and $10.2 \%$ to informal social participation, and $1.2 \%$ to the degree of exposure to information sources and the mass media.

Table 5: Regressive and multiple gradual upward correlation analysis of the relationship of the respondents' knowledge of small productive projects and the most important activities provided by the Social Fund for Development.

\begin{tabular}{|c|c|c|c|c|c|}
\hline Analysis steps & $\begin{array}{c}\text { The variables included in the } \\
\text { analysis }\end{array}$ & $\begin{array}{c}\text { Multiple } \\
\text { Correlation } \\
\text { Coefficient }\end{array}$ & $\begin{array}{c}\text { The cumulative percentage of } \\
\text { the variance explained to the } \\
\text { dependent variable }\end{array}$ & $\begin{array}{c}\text { The percentage of the } \\
\text { variance explained by the } \\
\text { dependent variable }\end{array}$ & $\begin{array}{c}\text { Regression } \\
\text { coefficient }\end{array}$ \\
\hline First step & $\begin{array}{c}\text { The participation's degree in the } \\
\text { activities of the social fund }\end{array}$ & 0.837 & 70.1 & 70.1 & 17.9 \\
\hline Second step & $\begin{array}{c}\text { The tendency's degree towards } \\
\text { small projects }\end{array}$ & 0.938 & 98 & 10.2 & 1.796 \\
\hline Third step & $\begin{array}{c}\text { The degree of informal social } \\
\text { engagement }\end{array}$ & 0.991 & 98.2 & 1.2 & 0.691 \\
\hline Fourth step & $\begin{array}{c}\text { The exposure's degree to } \\
\text { information sources and mass media }\end{array}$ & 0.997 & 99.4 & 0.396 \\
\hline
\end{tabular}

Note: Source: collected and calculated from field study data

Morale at level 0.01

The positive relationship between the degree of respondents' knowledge of information items related to small productive projects and the most important activities provided by the Social Fund for Development, can be explained by the greater the degree of the respondent's participation in the activities of the social fund, the degree of its direction towards small projects, the degree of its informal social participation, and the degree of its exposure to information sources and the media The greater the public's awareness of the importance of small productive projects and the greater their desire to obtain knowledge and innovations in this field, especially young female researchers who are expected to deal in the field of small projects for a period longer than the elderly and therefore they become more eager to increase their knowledge in this field. Among the previous results of the relationship of some of the independent variables under study related to the level of female researchers' knowledge of information items related to small productive projects and the most important activities provided by the Social Fund for Development, it is clear that the variables of the degree of participation in the activities of the social fund, the degree of trend towards small projects, the degree of informal social participation, and the degree of exposure Information sources and the mass media are among the best variables studied as facilities to know the respondents with information items related to small productive projects and the most important activities provided by the Social Fund for Development, which requires planners and implementers of extension programs related to increasing the knowledge of the female researchers in the field of small projects to pay attention to these variables in particular and that contribute to increasing Knowledge of research related to small productive projects and the most important activities provided by the Social Fund for Development, and the need for future studies to be aware of the other variables not covered in the study.

\section{The Most Important Problems Facing}

The most important problems facing female respondents who benefit from loans from the Social Fund for Development and their proposals to solve them: The results of the study also showed the existence of problems facing female researchers in the field of small productive projects. The most important of these problems was the scarcity of training programs appropriate to the nature of the project $(86.4 \%)$, the weak ability to pay the loan amount in the specified dates $(79.2 \%)$, the inability to market or export the product $(77.9 \%)$, lack of marketing experience for the beneficiaries (72.7\%), as shown in Table 6. The respondents also pointed to some proposals to overcome such problems, the most important of which is providing a database on investment projects, reducing procedures for disbursing the loan, providing transportation through cooperative marketing societies, and holding training courses for borrowers during their projects as shown in Table 7. 
Table 6: Problems facing female respondents who benefit from loans from the Social Fund for Development.

\begin{tabular}{|c|c|c|c|}
\hline $\mathbf{N}$ & The problems & Repetition & \% \\
\hline 1 & The scarcity of training programs appropriate to the nature of the project & 133 & 122 \\
\hline 2 & Inability to repay the loan amount on time & 120 & 79.2 \\
\hline 3 & Inability to market or export the product & 112 & 77.9 \\
\hline 4 & Lack of marketing experience for beneficiaries & 72.7 \\
\hline
\end{tabular}

Note: Source: field study data

Table 7: Suggestions for solving problems from the respondents' point of view In the field of small productive projects and the most important activities provided by the Social Fund for Development.

\begin{tabular}{|c|c|c|c|}
\hline $\mathbf{N}$ & The problems & Repetition & $\%$ \\
\hline 1 & Repetition and provision of a database on investment projects & 128 & 83.1 \\
\hline 2 & Short loan disbursement procedures & 117 & 76.0 \\
\hline 3 & Providing transportation through cooperative marketing associations & 114 & 74.0 \\
\hline 4 & Holding training courses for female borrowers during their projects & 110 & 71.4 \\
\hline
\end{tabular}

Note: Source: field study data

\section{Summary}

Based on the results of the research, the application benefits can be summarized as follows: In light of the results shown by a decrease in the knowledge of the respondents, as these results indicate that $74.7 \%$ of the respondents were of low and medium knowledge of the information items on small productive projects and the most important activities provided by the Social Fund, the research draws the attention of planners and implementers of extension programs and fund programs The social development focus on increasing activities and indicative efforts to educate the respondents about the knowledge of small projects so that this knowledge can be applied and thus obtain a high income and return that provides the rural women with a stable life. The need for planners and implementers of future extension programs aimed at increasing rural women's knowledge of small productive projects and the most important activities provided by the Social Fund to be concerned with the following variables: degree of participation in social fund activities, degree of trend towards small projects, degree of informal social participation, and degree of exposure to information sources The mass media, as having a high impact on the knowledge of rural women, are predicting the extent of this change in the future. The necessity that future research related to the behavior of rural women in the field of small productive projects be concerned with studying the personal and situational variables that were not included in the research, and that they may have a significant contribution to the overall explanatory variation of the change in rural knowledge in the study area and other similar areas.

\section{References}

1. Ghanem, Abdul Rahman Ahmed (1990) The role of civil cooperatives in rural development in the Yemen Arab Republic, PhD thesis, Department of Agricultural Economics, Faculty of Agriculture, Mansoura University, Egypt.

2. Social Fund for Development, Agricultural Annual Report, General Administration of Planning and Follow-up, Sana'a, from 2006-2014.

3. Alexander, Naguib (1997) Political Decision and Literacy Campaigns. Journal of Mass Education, (PhD), Fourth Year 9: 83.

4. Al-Sayyad, Abdel-Baset, Salem, Hussein Salem (1990) An analytical study of the effects of Agricultural Development and Credit Bank projects in the Dakahlia Governorate, (Ph.D.). published research, $\mathrm{Al}$ Azhar Magazine, twelfth issue, Cairo.

5. Al-Sayed, Nusrat Al-Zaki (2006) Economic and Social Impact of NGOs in the Development of Rural Women, Case Study of the Rural Development Project (IFAD-ADS) in North Kordofan State, Master Thesis, Omdurman Islamic University, Sudan.
ISSN: 2574-1241

DOI: 10.26717/BJSTR.2021.37.005977

Haifa Al-Sanabani. Biomed J Sci \& Tech Res

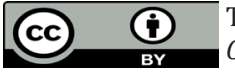

This work is licensed under Creative

Commons Attribution 4.0 License

Submission Link: https://biomedres.us/submit-manuscript.php

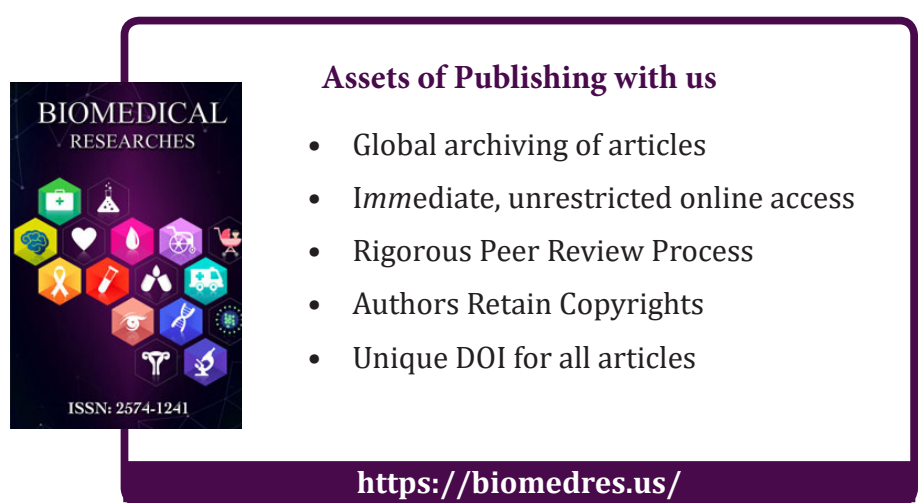

